\title{
The analysis and research on variable operating condition of exhaust steam and waste heat Cascade utilization system of air cooling heating unit
}

\author{
Ning Zhao ${ }^{1^{*}}$, Xiaoying Fan $^{2}$, Lite Ji ${ }^{2}$ and Ya-mi Chen ${ }^{3}$ \\ ${ }^{1}$ North China Electric Power Research Institute Co., Ltd. Beijing 100045, China \\ ${ }^{2}$ Nei Meng Gu Sheng Le Thermoelectric Co., Ltd. . Huhehaote 011517, China \\ ${ }^{3}$ North China Institute of Science and Technology, Beijing, 101601, China
}

\begin{abstract}
The series and parallel exhaust heat cascade utilization system was adopted by the large direct air cooling heating units. On the one hand, this system could reduce the adverse impact on power generation; on the other hand, it could reduce the temperature difference of heat transfer through step by step heating, the irreversible loss could be reduced, and the energy utilization efficiency could be made higher. On the basis of grasping the design performance of exhaust steam utilization system and the variable operating performance of main equipment by analysing the data of typical operating conditions, the optimization analysis model of heat pump group and the whole plant was established by this paper. The performance of heat pump unit under variable operating conditions was analysed and calculated, the influence of different exhaust pressure and backwater temperature on the economy of the whole machine was analysed, and the optimal operation mode of the heat pump was obtained. Finally, the pumping and condensing ratio curves under different conditions of winter heating conditions were determined, which could guide the optimal operation of heat pump units. It also provided technical support and basis for deep peak regulation or flexible transformation of heating units.
\end{abstract}

\section{Introduction}

China's macro economy was in the stage of economic restructuring, the economic growth rate has entered a shift period, and economic development has entered a "new normal". Policies on energy conservation and emission reduction and power supply structure adjustment have led to the rapid development of clean energy such as hydropower, wind power and solar power. However, the randomness and volatility of wind power generation output were strong, it basically could not match the load, and the peak load cutting capacity was weak. The intermittent and volatility characteristics solar energy determine its output was difficult to ensure stability. Therefore, the new energy sources such as wind power and solar energy were integrated into the grid on a large scale and continued to grow, which increased the pressure and difficulty of peak regulation in the power grid system. Therefore, in the absence of other more effective peak regulation means, it would be a long-term task for the coal power units to take charge of peak regulation. However, in winter, the cogeneration units were responsible for most of the city's heating load, the state also needed to accelerate the development of cogeneration units in order to ensure people's livelihood and environmental protection. At the same time, it was accompanied by some problems, such as the contradiction between the operation mode of heating units and the peak regulation of the units. According to the statistical data, the minimum electrical load of thermoelectric units in winter was $60 \%$ of rated load, and the electrical load should increase correspondingly with the increase of thermal load.

At present, the problem of peak regulation of heating units could be improved by recycling waste heat of the units. There were two common waste heat recovery schemes in power plants, one was steam turbine lowvacuum operation technology, and the other was heat pump recovery waste heat technology. No matter what kind of operation mode was adopted, the exhaust temperature and corresponding saturation pressure of the steam turbine would change, which would lead to the change of exhaust pressure, which was, the change of vacuum degree, the flow rate and power of the unit was affected. However, when the power generated by the saved steam extraction capacity was used for power generation, the increased power generation offsets or even exceeds the reduced power generation caused by the increase of condenser pressure, the advantages of using waste heat for heating could be shown. Therefore, under the condition that the heating load remains unchanged, the maximum power generation load was larger than the maximum power generation load of the traditional combined heat and power generation, that was to say, the power load of the unit could be relatively reduced.

\footnotetext{
*Corresponding author's e-mail: zn77816@sina.com
} 
In addition, the average thermal energy utilization rate of power plants in China was relatively low, most of the thermal energy was discarded into the environment through different forms in the process of power generation, and the energy utilization efficiency was low, simultaneously caused the massive pollution to the environment. The largest proportion of abandoned thermal energy was steam turbine exhaust, accounting for about $40 \%$ of the total input thermal energy, which was especially serious in direct air cooling units. If this part of heat could be reasonably used, it was of great significance to improve the thermal efficiency of power plants and protect the environment. Therefore, if condensation waste heat was used for heating, domestic hot water, waste heat recovery of units, etc., it could not only reduce the loss of water evaporation and environmental thermal pollution caused by condensation and heat dissipation of power plants, but also alleviated the shortage of resources caused by heating. At the same time, the cascade utilization of energy was realized, the comprehensive utilization efficiency of energy was improved, it could make coal-fired power plants adapt to electricity market operation and improve the advantage of price competition.

\section{The system analysis of exhaust steam and waste heat utilization of air cooling heating unit}

The waste heat utilization system of a plant was shown in figure 1, there were four units: a $2 \times 220 \mathrm{MW}$ unit and a $2 \times 300 \mathrm{MW}$ unit. Each host corresponds to a heat pump, and each heat pump was separately equipped with waste heat recovery room to recover waste heat from steam turbine exhaust. The design exhaust pressure of two heating units was different, the exhaust pressure of unit 2

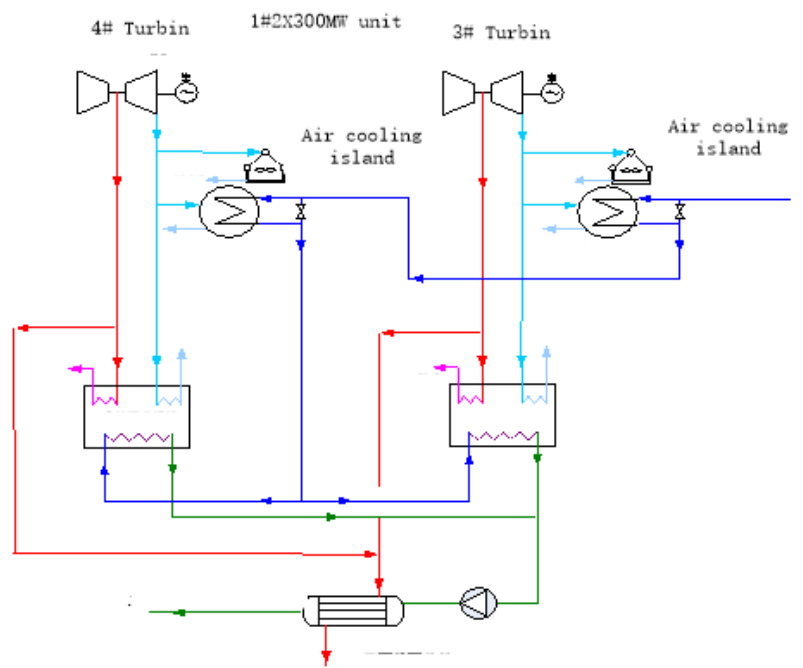

and 4 was higher than that of unit 1 and 3 . The front heat exchanger was in series, the absorption heat pumps were in parallel. The water in the heat network was heated successively through the pre-heat exchanger, absorption heat pump and peak heater, and then was sent to the urban heat network. The system made full use of the 2\# and $4 \#$ units with high exhaust pressure to provide heat, and the condensate waste heat of the unit was extracted as far as possible, and the thermal efficiency of the unit was improved. 1\# and 3\# units with low exhaust pressure were used to generate electricity, the unit only beared part of the steam extraction load, the whole heating season as a peak adjustment operation. In the early and late cold period, the amount of exhaust steam on the tower of $2 \#$ and $4 \#$ units with high back pressure was small, Low pressure cylinder exhaust steam condensate waste heat was all recovered, Air cooling island isolation valve has been closed, there was no risk of freezing. With the transition from the cold period to the early and late cold period, the exhaust amount of air condensing steam to the air condensing steam was increased. In the system operation, it was only necessary to concentrate on monitoring the air condensing steam of unit 1 and unit 3 .

In order to determine the operation and removal of steam exhaust waste heat recovery heating system economic comparison, the comparison of economic data between operation and removal of exhaust heat utilization system was carried out. The economic relationship between vacuum and exhaust heat utilization unit was compared under different working conditions, so as to find the best operating condition and mode. The economic analysis results of exhaust steam waste heat recovery were shown in the following table.

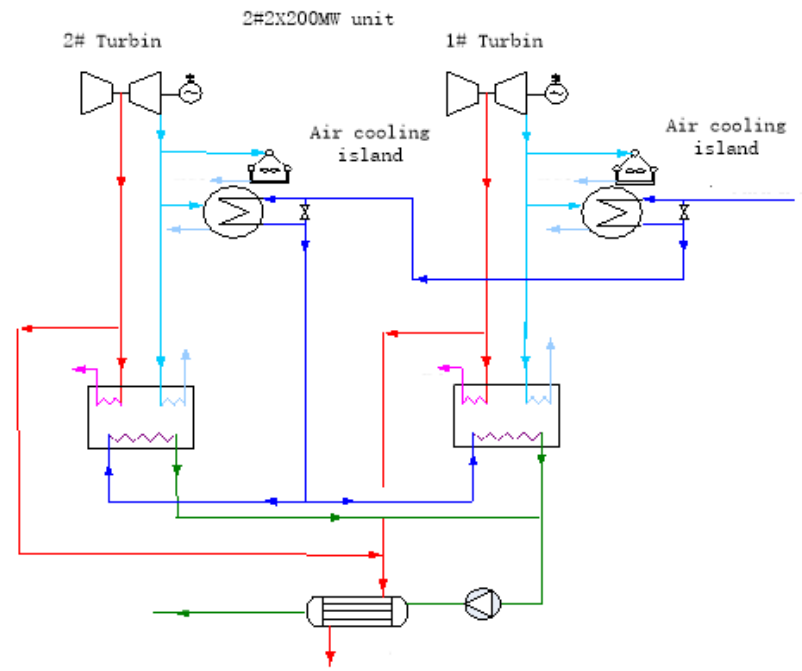

FIG. 1 Flow diagram of waste heat recovery and utilization system of the whole plant 
Table 1. Economic analysis of exhaust steam waste heat recovery of 200MW unit (Turbine comparison).

\begin{tabular}{cccccc}
\hline Project & Unit & Operating system & Shut down the system & Operating system & Shut down the system \\
Power & $\mathrm{MW}$ & 140.77 & 140.28 & 140.29 & 142.09 \\
Exhaust pressure & $\mathrm{kPa}$ & 25.39 & 24.97 & 20.14 & 20.83 \\
test heat consumption rate & $\mathrm{kJ} / \mathrm{kWh}$ & 6213.23 & 7735.91 & 7576.92 & 6241.62 \\
Corrected heat consumption rate & $\mathrm{kJ} / \mathrm{kWh}$ & 6056.74 & 7549.81 & 7505.06 & 6174.50 \\
Auxiliary power & $\mathrm{MW}$ & 14.87 & 14.88 & 15.09 & 15.09 \\
Total heat by waste heat & GJ & 194.74 & 10.14 & 7.70 & 221.95 \\
Total heat by heat pump & GJ & 73.43 & 9.79 & 7.66 & 78.21 \\
Total heat by front condenser & GJ & 123.75 & 18.14 & 0.00 & 79.11 \\
\hline
\end{tabular}

Table 3. Economic analysis results of exhaust steam waste heat recovery (heat pump).

\begin{tabular}{ccccc}
\hline Project & Unit & Operating system 15kPa & Operating system 20kPa & Operating system 25kPa \\
\cline { 1 - 2 } $\begin{array}{c}\text { Drain water flow of heat pump } \\
\text { Recover total heat of exhaust } \\
\text { steam by 1\# heat pump }\end{array}$ & GJ & 109.21 & 108.51 & 108.49 \\
$\begin{array}{c}\text { Recover total heat of exhaust } \\
\text { steam by 2\# heat pump }\end{array}$ & GJ & 160.58 & 175.08 & 195.93 \\
COP of 1\# heat pump & 149.75 & 1.82 & 159.94 & 187.41 \\
COP of 2\# heat pump & & 1.80 & 1.89 & 1.89 \\
\hline
\end{tabular}

It could be known from the data results of typical working conditions, before and after the system was put into operation, the heat consumption difference of $300 \mathrm{MW}$ host when the exhaust pressure was $15 \mathrm{kPa}$, $20 \mathrm{kpa}$ and $25 \mathrm{kpa}$ was shown in figure 7 , and the corresponding recovered heat was shown in figure 2 . It could be seen from the figure that under the current load and environmental conditions, the overall economy was better when the back pressure was about $20 \mathrm{kPa}$. At the

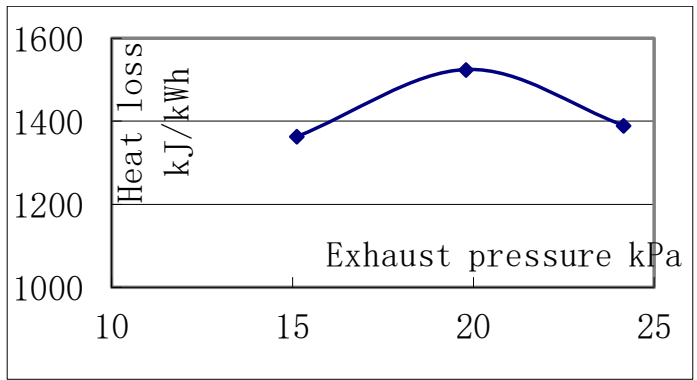

FIG. 2 Influence of exhaust pressure on heat loss

Similarly, under the current load and environmental conditions, the overall economy of $200 \mathrm{MW}$ unit was better when the exhaust pressure was about $25 \mathrm{kPa}$. The auxiliary power rate could be reduced by $0.15 \%$ at $20 \mathrm{kPa}$ exhaust pressure and $0.05 \%$ at $25 \mathrm{kPa}$ exhaust pressure. When the exhaust steam waste heat recovery heating system was put into operation, the waste heat utilization of the precondenser was $35 \% \sim 60 \%$.

\section{Optimization operation of exhaust heat utilization system}

same thermal and electrical loads, under $15 \mathrm{kPa}$ exhaust pressure, the operation of exhaust steam waste heat recovery heating system could reduce power consumption by $0.013 \mathrm{MW}, 0,798 \mathrm{MW}$ under $20 \mathrm{kPa}$ exhaust pressure, and $0.366 \mathrm{MW}$ under $25 \mathrm{kPa}$ exhaust pressure. When the exhaust steam waste heat recovery heating system was put into operation, the waste heat utilization of the front condenser was $17 \% \sim 25 \%$.

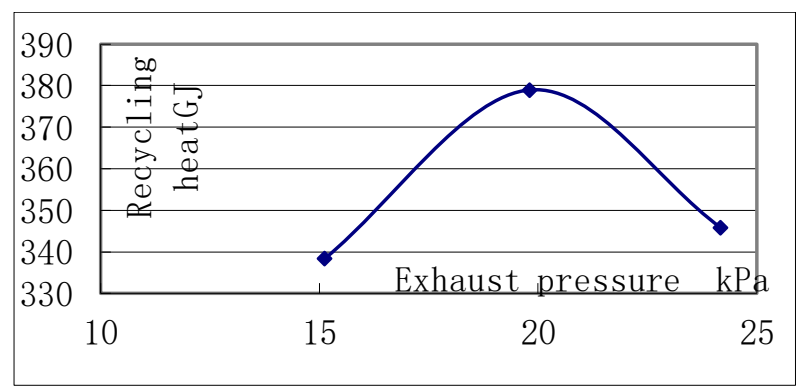

FIG. 3. Influence of exhaust pressure change on heat recovery of the unit

After all, data analysis of typical working conditions could only be a few discrete working conditions, In order to understand the operating characteristics of steam turbine with exhaust steam and waste heat utilization system in detail, it was necessary to calculate the variable operating condition of steam turbine. In this paper, the thermal economic equation of state was used to calculate the variable operating conditions of steam turbine configured with exhaust heat utilization system.

Through the statistical analysis of the annual operation data of the power plant, the trend of circulating water flow in the $1 \#$ heat network of the unit during the heating period could be obtained, as shown in figure 4 . 
The circulating water flow trend of $1 \#$ heat network was shown in figure 5 . The thermal load required by the

It could be seen that the heat network water flow in the heating period could be basically divided into three stages. In the early stage of heating, the water flow in the heat network of no. 1 was $3000 \mathrm{t} / \mathrm{h}$, the water flow in the heat network of no. 2 was $3500 \mathrm{t} / \mathrm{h}$, and the total water flow in the $1 \#$ heat network was about $6500 \mathrm{t} / \mathrm{h}$, the water flow rate of the heat network of no. 3 was $4300 \mathrm{t} / \mathrm{h}$, the water flow rate of the heat network of no. 4 was $4000 \mathrm{t} / \mathrm{h}$, and the total water flow rate of the $2 \#$ heat network was about $8300 \mathrm{t} / \mathrm{h}$. During the period of high load in the middle stage of heating, the water flow rate of no. 1 heat network was $3200 \mathrm{t} / \mathrm{h}$, the water flow rate of no. 2 heat

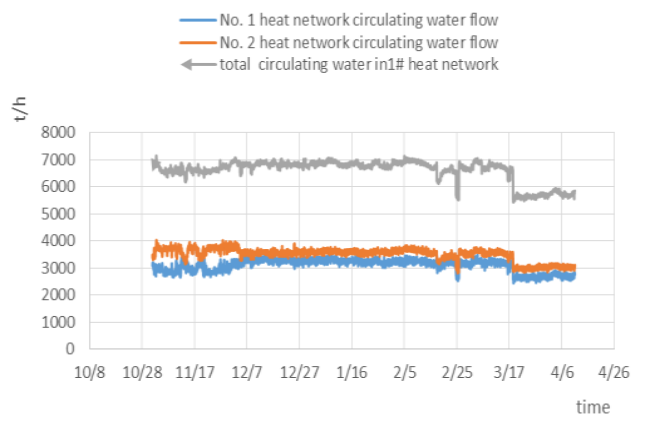

FIG. 4 Change trend of circulating water in Heating network in the heating period of no. 1 whole plant was shown in figure 6 .

network was $3800 \mathrm{t} / \mathrm{h}$, and the total water flow rate of $1 \#$ heat network was about $7000 \mathrm{t} / \mathrm{h}$. The water flow of no. 3 heat network was $4800 \mathrm{t} / \mathrm{h}$, the water flow of no. 4 heat network was $4200 \mathrm{t} / \mathrm{h}$, and the total water flow of $2 \#$ heat network was about $9000 \mathrm{t} / \mathrm{h}$. At the end of heating, the water flow of no. 1 heat network was $2500 \mathrm{t} / \mathrm{h}$, the water flow of no. 2 heat network was $3000 \mathrm{t} / \mathrm{h}$, and the total water flow of $1 \#$ heat network was about $5500 \mathrm{t} / \mathrm{h}$. The water flow of no. 3 heat network was $3900 \mathrm{t} / \mathrm{h}$, the water flow of no. 4 heat network was $3100 \mathrm{t} / \mathrm{h}$, and the total water flow of $2 \#$ heat network was about $7000 \mathrm{t} / \mathrm{h}$.

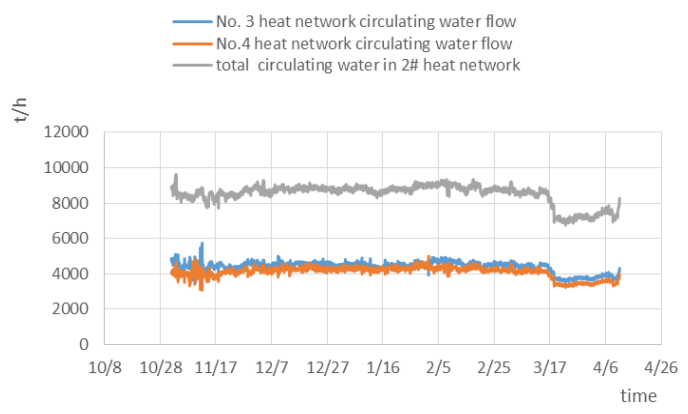

FIG. 5 Change trend of circulating water in heating network in the heating period of no. 2

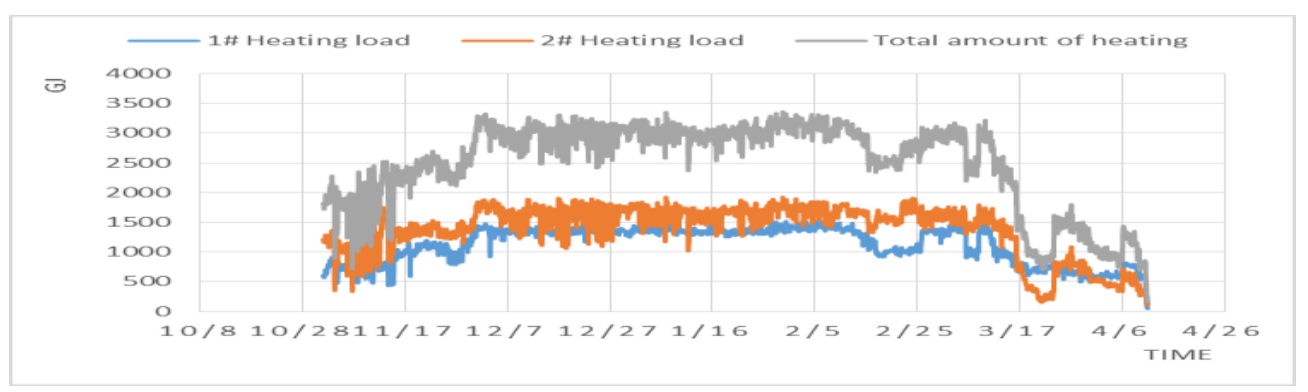

FIG. 6 Variation trend of heating load in heating period

The same thing could be seen in the figure above, in the initial stage of heating, the heating quantity of $1 \#$ was $600 \mathrm{GJ} / \mathrm{h}, 2 \#$ was $1200 \mathrm{GJ} / \mathrm{h}$, and the total heating quantity of the whole plant was about $1800 \mathrm{GJ} / \mathrm{h}$; In the middle of heating, the heating quantity of $1 \#$ was $1300 \mathrm{GJ} / \mathrm{h}, 2 \#$ was
$1700 \mathrm{GJ} / \mathrm{h}$, and the total heating quantity of the whole plant was about $3000 \mathrm{GJ} / \mathrm{h}$; at the end of heating, the heating quantity of $1 \#$ was $650 \mathrm{GJ} / \mathrm{h}, 2 \#$ was $500 \mathrm{GJ} / \mathrm{h}$, and the total heating quantity of the whole plant was about $1050 \mathrm{GJ} / \mathrm{h}$.
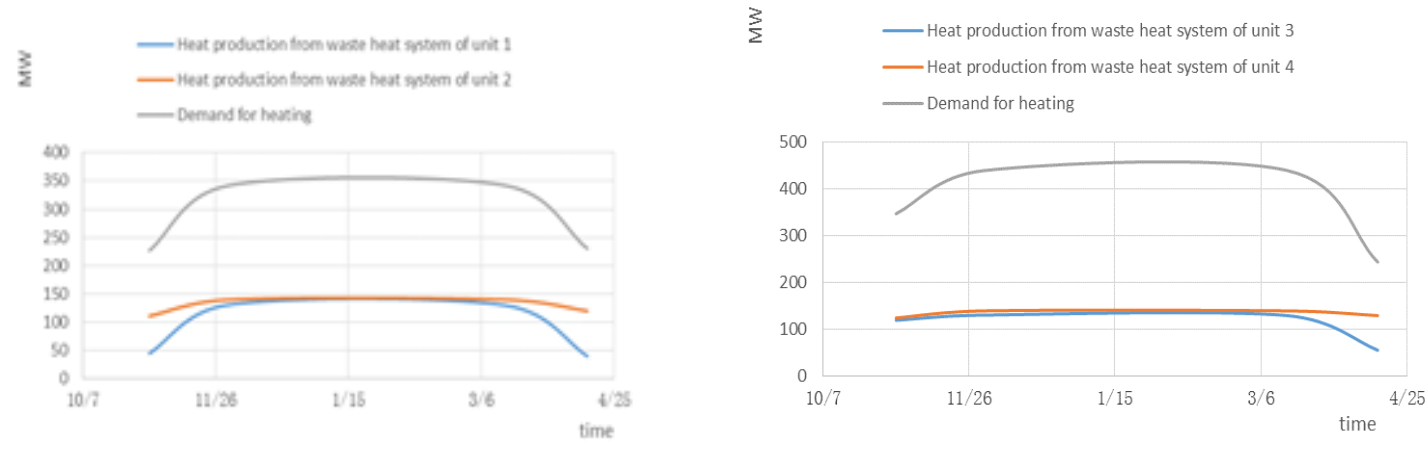
FIG. 7 1\# relation curve between waste heat recover and heat supply of heating units

Based on the above statistical data, the unit with waste heat utilization system was analysed through the calculation method of heat state equation in variable condition, and the optimized heat supply relation curve with the variation of heating quantity could be obtained, as shown in FIG. 7, 8.

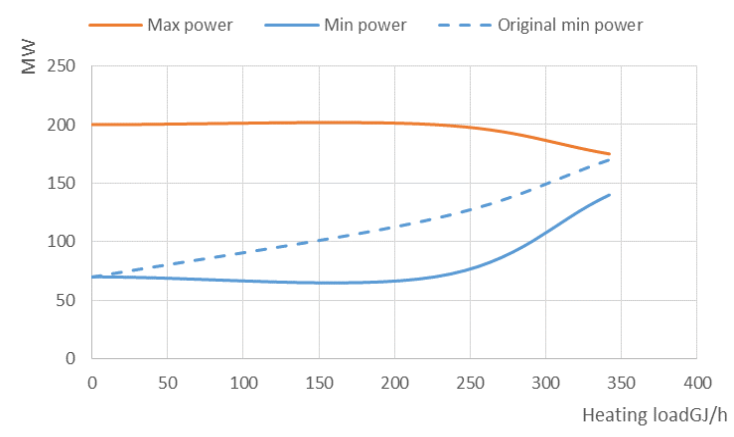

FIG. 13 Peak load regulation range curve of 300MW

\section{Conclusion}

The three-stage cascade heating network to circulate water was adopted by the large direct air cooling heating unit. With the increase of circulating water temperature of the heating network, the heating energy level also was increased gradually, and the efficiency of the whole heat exchange link could be greatly improved. The three-stage cascade makes full use of low-grade exhaust waste heat, realizes energy level matching in heat transfer process, greatly reduces irreversible loss in heat transfer process, and improves economy. The waste heat of low-grade exhaust gas was fully utilized by the three steps, the energy level matching of heat transfer process was realized, the irreversible loss of heat transfer process was greatly reduced, and the economy was improved. In addition, two steam turbines of the same type had different operating exhaust pressure, the average operating exhaust pressure of the two turbines was reduced. On the one hand, the adverse impact on power generation was reduced; on the other hand, the heat transfer temperature difference was reduced through step-by-step heating, the irreversible loss was reduced and energy utilization efficiency has been improved.

\section{Acknowledgments}

This paper was supported by North China Electric Power Research Institute Co., Ltd.

\section{References}

1. National bureau of statistics. (2015) Statistical bulletin on national economic and social development.
FIG. 8 2\# relation curve between waste heat recovery and heat supply of heating units

The new peak regulation curve of heat supply could be obtained by applying the optimized exhaust waste heat utilization system. It could be seen that the peak load adjustment range of the optimized units has also increased a lot, thus reducing the pressure of peak load adjustment in winter.

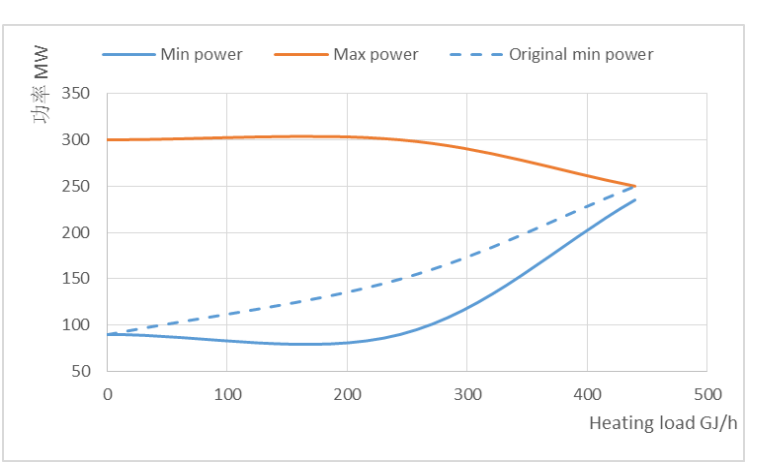

FIG. 14 Peak load regulation range curve of 200MW

2. Meyer, B. Distributed Generation (2007). Towards an effective contribution to power system security. Power Engineering Society General Meeting.: 1-6.

3. Chen Li, Chen Geheng (2005). The setting of peak load regulating power supply. Jiangsu electrical engineering, (6) : 43-45.

4. Lu Xueqin, Liu Gang, Huang Ziyuan. (2007) Peak load regulation and its problems. Power station system engineering, 23 (5): 37-40.

5. Shen Zhewei. (2013) Study on peak load distribution of thermal power units. Beijing : North China electric power university.

6. Wang Haining. (2012) Analysis of economy and safety of deep peak regulation operation and load optimization distribution of large coal-fired power units. Beijing: North China electric power university.

7. Li Jinzhao. (2004) Study on peak regulation mode of domestic 300MW thermal power unit. Baoding: North China electric power university.

8. Hong Jun, Zhang Baoheng. (1992) Study on optimization of peak-regulating operation scheme of thermal power unit. Journal of north China electric power institute, 47-52.

9. Yang Jiming. (2004) Requirements for boiler equipment and operation technology for peak load regulation. Boiler technology, 35(3): 59-63.

10. Wang Kai, Huang Baohua, Si Paiyou. (2012) Study on influencing factors of peak adjustment margin of thermal power units. Energy saving technology, 30(171) 52-58.

11. Cao Zuqing . (1991) Variable operating characteristics of steam turbine . Beijing: water resources and electric power press. 